\title{
Surgical anatomy for Asian rhinoplasty: Part II
}

Taek Kyun Kim, Jae Yong Jeong

The PLUS Plastic Surgery Clinic, Seoul, Korea
Surgical anatomy for Asian rhinoplasty Part I reviewed layered anatomy with neurovascular system of the nose. Part II discusses upper two-thirds of nose which consists of nasal bony and cartilaginous structures. Nasal physiology is mentioned briefly since there are several key structures that are important in nasal function. Following Part III will cover lower one-third of nose including in-depth anatomic structures which are important for advanced Asian rhinoplasty.

Keywords: Keystone area / Nasal bone / Nasolacrimal duct / Pyriform aperture / Rhinoplasty / Septum / Turbinate / Upper lateral cartilage

\section{BONY PYRAMID}

\section{Nasal bones}

The paired nasal bones are located at the upper-middle of the vertical axis and are supported by the bony septum. They are superiorly connected to the nasal process of the frontal bone, laterally with the frontal process of the maxilla, and inferiorly with the pyriform aperture. The nasal bones and the frontal process of the maxilla form the nasal bony framework, which is referred to as the bony vault (Fig. 1). The thickness of the bone differs depending on its location within the bony vault, as the thickest bone is found in the cephalic radix. The thickness of bone can be revealed through trans-illumination [1-3]. The three-dimensional shape of the lateral part of the bony configuration is essential to consider when planning lateral osteotomy procedures. The nasal bones and the frontal process of the maxilla may have straight, convex, or concave configurations $[4,5]$.

The radix area consists of the nasal bone, the frontal bone, and the spine of the frontal bone. These bones are connected as a solid syndesmosis with erasure of the original midline suture lines; thus, reduction of this solid bony mass is difficult, and os-

Correspondence: Taek Kyun Kim

The PLUS Plastic Surgery Clinic, 9 Dosan-daero 13-gil, Gangnam-gu, Seoul 06035, Korea

E-mail: psheroh2@naver.com

Received June 2, 2020 / Revised June 3, 2020 / Accepted June 4, 2020 teotomies extending to this area are at risk for "rocker formations" [4]. In clinical settings, it is impossible to check the nasion, which is the depression at the nasal root corresponding to the midpoint of the frontonasal suture. Instead, clinicians analyze the sellion, which is the deepest point of the frontonasal angle that is visible from a person's external appearance. The sellion is located slightly below the nasion, within 9-14 mm from the projected point of the cornea in Caucasian faces gazing anteriorly [6]. The ideal location of the sellion is considered to be between the double eyelid line and the upper eyelid margin. A level upper eyelid margin is ideal in Asian faces, with variation according to each patient's condition and desires (Table 1, Fig. 2) [6,7].

\section{Pyriform aperture}

The nasal pyriform aperture is the anterior boundary of the na-
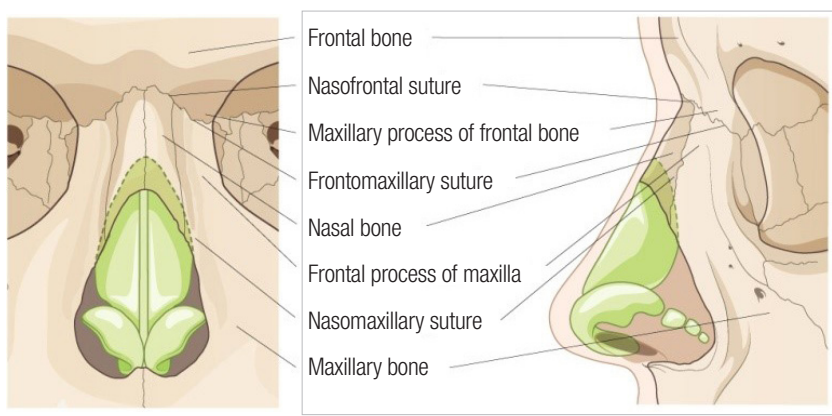

Fig. 1. Anatomy of the nasal bony framework (the bony pyramid). 
Table 1. Surface landmarks of the lateral profile

\begin{tabular}{ll}
\hline Landmark & \multicolumn{1}{c}{ Definition } \\
\hline $\begin{array}{l}\text { Radix (nasal root) } \\
\text { Nasion }\end{array}$ & $\begin{array}{c}\text { Junction between the frontal bone and the dorsum of the nose. } \\
\text { A depression at the root of the nose corresponding to the } \\
\text { nidpoint of the frontonasal suture. }\end{array}$ \\
Sellion & $\begin{array}{c}\text { The deepest point of the nasofrontal angle at the intersection } \\
\text { of the forehead slope and the proximal nasal bridge. } \\
\text { Known as the soft tissue nasion. }\end{array}$ \\
Rhinion & $\begin{array}{c}\text { A landmark in cephalometry, the lower end of the suture } \\
\text { between the nasal bones. }\end{array}$ \\
\hline
\end{tabular}
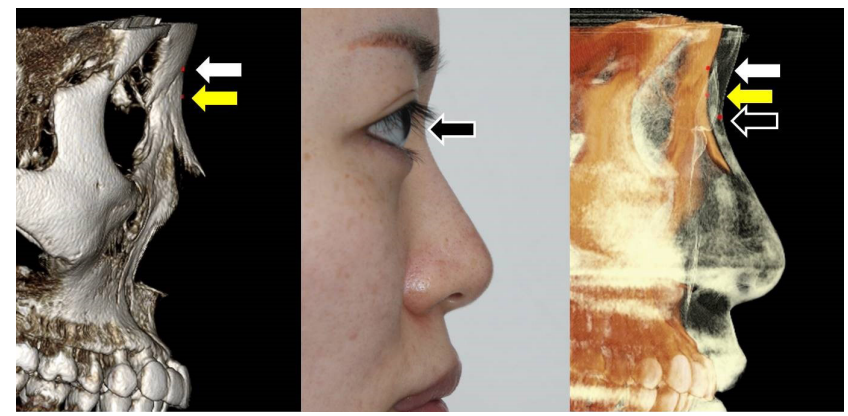

Fig. 2. Landmarks in the lateral view. Nasofrontal suture (white arrow), nasion (yellow arrow), and sellion (black arrow).

sal skeleton. The maxillary bone forms the inferior and lateral borders of the pear-shaped aperture, while the nasal bone is its superior border. The medial border is formed by the rounded edge of the premaxilla bone and the sharper edge of the maxilla. These two bones fuse anteriorly to form the anterior nasal spine (Fig. 3) [8].

The size and shape of the nasal bone and pyriform aperture vary according to sex and race (Fig. 4) [8]. In cold and dry environments, a long nasal bone with a narrow pyriform aperture is suitable for controlling the temperature and humidity of inhaled air. Lang and Baumeister [9] classified the nasal bones of the German population into eight groups and reported that the length of the nasal bone was $24.9 \pm 3.2 \mathrm{~mm}$ and the width of the pyriform aperture was $23.6 \pm 1.8 \mathrm{~mm}$. Of odile [10] also measured the length of the nasal bone and the width of the pyriform aperture in 20 skulls, of which six were from the Ashanti tribe in West Africa, five from Austria in Northern Europe, five from black Americans, and four from American Indians. He reported that the nasal bone length in the skulls from Austria was $30.2 \mathrm{~mm}$ (range, $29-31 \mathrm{~mm}$ ) and the width of the pyriform aperture was $21.6 \mathrm{~mm}$ (range, 17-24 mm). The Ashanti skulls had oval pyriform apertures, whereas those in European and American Indian skulls were triangular. However, both oval and triangular shapes were found in the black American skulls. Hwang et al. [11] studied nasal bones in Koreans and classified them into five groups. According to his findings, the length of

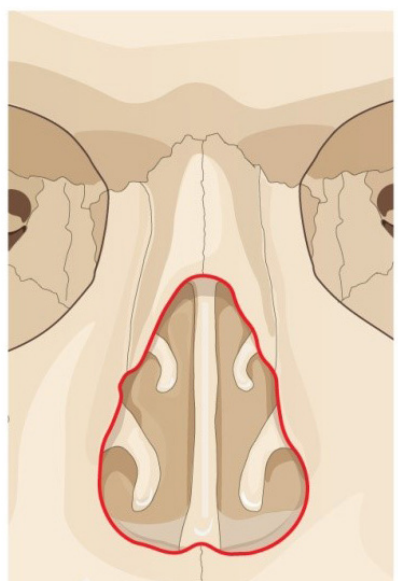

(A)

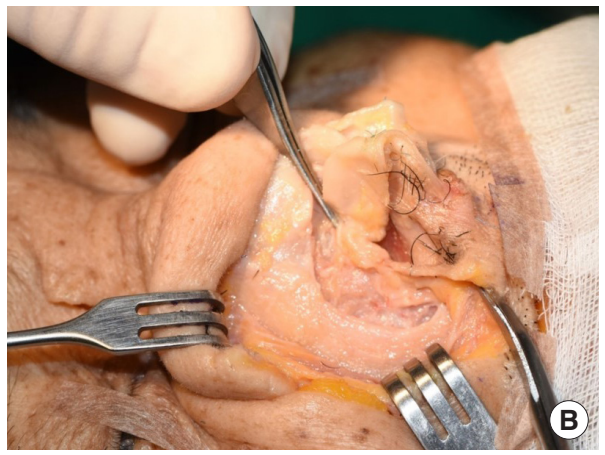

Fig. 3. Pyriform aperture. (A) Illustration (red line). (B) Cadaver.

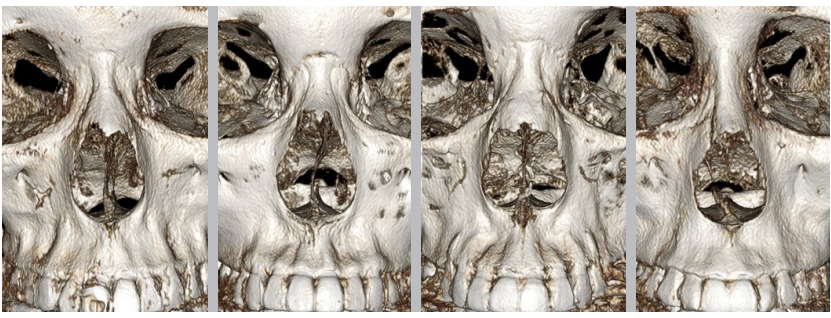

Fig. 4. Various shapes and sizes of the pyriform aperture on computed tomography scans.

the nasal bone in Koreans was $25.9 \pm 3.8 \mathrm{~mm}$ in males and $24.5 \pm 3.7 \mathrm{~mm}$ in females, while the width of the pyriform aperture was $25.7 \pm 1.7 \mathrm{~mm}$ in males and $25.4 \pm 2.1 \mathrm{~mm}$ in females. Another study reported the morphology of the nasal bone and pyriform aperture in Koreans using three-dimensional computed tomography (CT). The mean thickness of the lateral osteotomy point was $2.03 \pm 0.35 \mathrm{~mm}$ and that of the medial osteotomy point was $1.75 \pm 0.37 \mathrm{~mm}$. The mean length of the nasal bone was $20.95 \pm 5.99 \mathrm{~mm}$ and the width of the pyriform aperture was $24.01 \pm 2.34 \mathrm{~mm}$ [5].

There is a risk of nasal cavity obstruction after nasal osteotomy if the osteotomized segment contains the lowest point of the pyriform aperture, which could consequently include the inferior turbinate. In 1977, Webster et al. [12] suggested that a triangle of 
bone, known as Webster's triangle, should be preserved at the base of the pyriform aperture below the inferior turbinate to maintain airway patency (Fig. 5). They proposed directions of osteotomy with anterior and superior vectors using a curved lateral osteotome, which is currently referred as the "high-lowhigh" lateral osteotomy. Guyuron [13] agreed with using this method since functional problems in airway patency arise if the head of the inferior turbinate reduces the pyriform aperture. In contrast, Gubisch [14] did not consider the efficiency of the preservation of the bony triangle to be an important issue (Fig. 6).

\section{Nasolacrimal duct}

The lacrimal groove, which protects the lacrimal sac, is formed by the posterior margin of the frontal process of the maxilla and the lacrimal bone. The height of the sac is $12-15 \mathrm{~mm}$, and its antero-posterior length is $4-8 \mathrm{~mm}$ [15]. The lacrimal sac lies inside the lacrimal fossa, and it is attached tightly to the periosteal lining of the fossa at the medial aspect. The lacrimal fossa is located antero-laterally at the anterior tip of the middle turbinate, draining inferiorly into the nasolacrimal duct. The nasolacrimal duct adjoins with the palatine bone and inferior turbinate medially and the maxillary bone laterally (Fig. 7). In females, the lower nasolacrimal fossa and the nasolacrimal duct are narrower, increasing the risk of nasolacrimal obstruction [16]. The bony course of the nasolacrimal duct (interosseous length: $12 \mathrm{~mm}$ ) runs to the inferior turbinate infero-laterally and slightly posteriorly. The long axis of the duct and canal has an angle of $15^{\circ}$ to $25^{\circ}$ posteriorly from the frontal plane, or on the line from the medial commissure to the first molar tooth $[17,18]$. The passage of the nasolacrimal duct ends at the inferior meatus, beneath the inferior turbinate. A mucosal fold, known as the valve of Hasner, partially covers the inferior meatus. A report has described the existence of multiple mucosal folds and sinuses in the lacrimal drainage system, but their distribution and role are not clearly understood. The valve of Hasner may be present at the end of the nasolacrimal duct inside
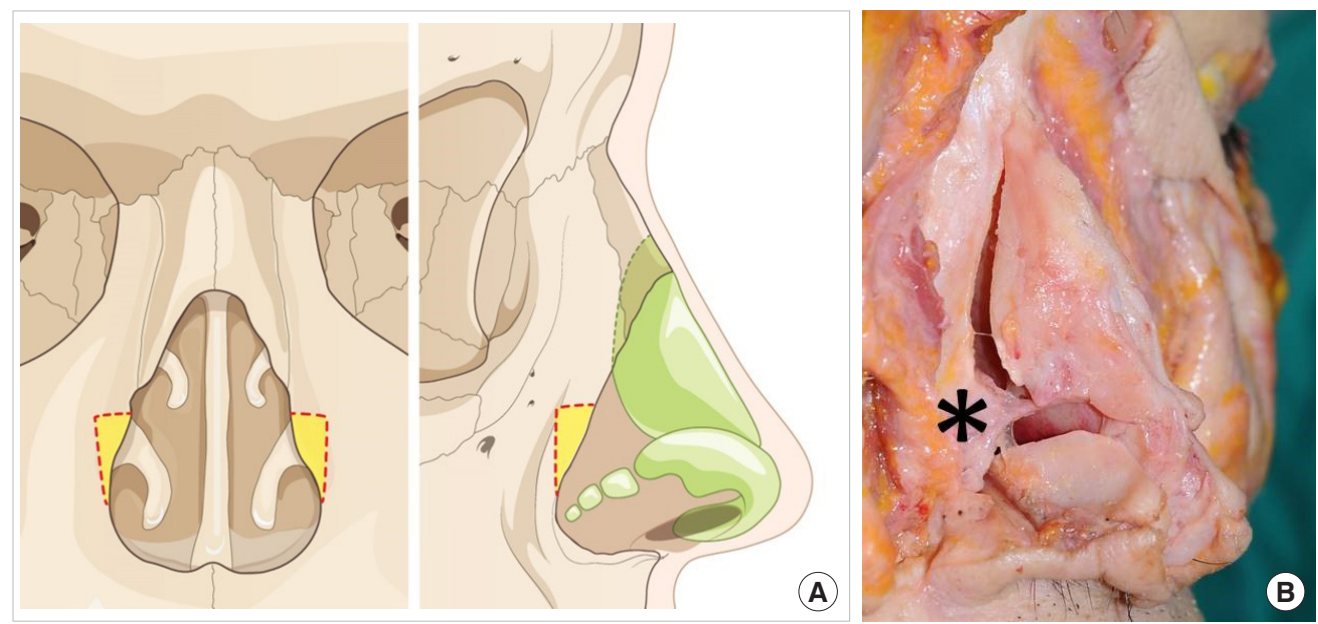

Fig. 5. Webster's triangle. (A) Illustration (yellow area). (B) Cadaver (asterisk).
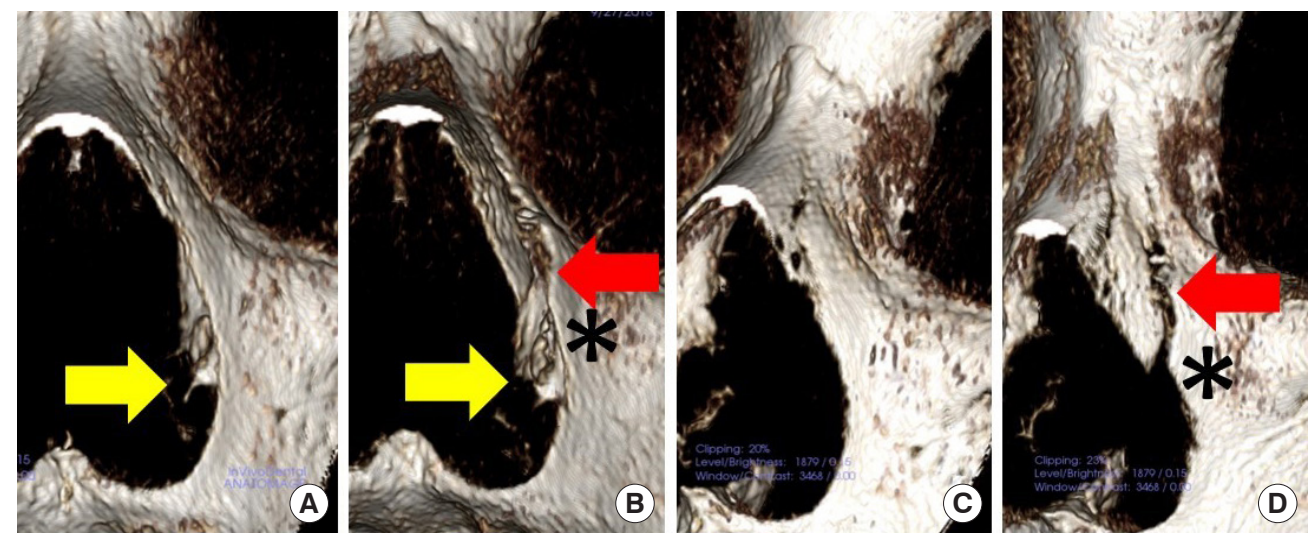

Fig. 6. Spatial relationship between the line of lateral osteotomy (red arrow) and the neck of the inferior turbinate (yellow arrow) and Webster's triangle (asterisk) on a computed tomography scan. (A) Before lateral osteotomy in the frontal view. (B) After lateral osteotomy. (C) Before lateral osteotomy in the oblique view. (D) After lateral osteotomy in the oblique view. 

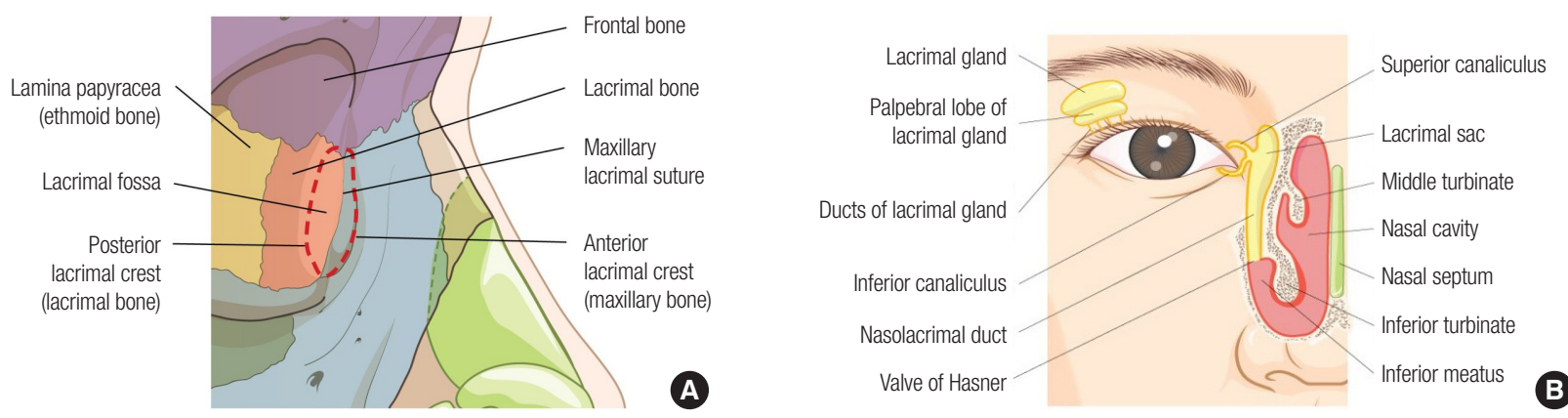

Fig. 7. Nasolacrimal system. (A) Bony anatomy around the nasolacrimal system. The lacrimal fossa (red dotted line) consists of the lacrimal bone, maxillary bone, and frontal bone. The anterior lacrimal crest and posterior lacrimal crest surround the lacrimal fossa. (B) Lacrimal drainage system. It starts from the superior and inferior canaliculi, runs though the nasolacrimal duct, and ends at the inferior meatus.

the nasal inferior meatus. The opening of the nasolacrimal duct is positioned posteriorly $25-30 \mathrm{~mm}$ from the lateral border of the anterior nares. The surgeon must be careful to avoid damaging the lacrimal sac during a low-to-low lateral nasal osteotomy, but iatrogenic damage of the lacrimal sac is uncommon unless the osteotomy line runs too deep during a lateral osteotomy (Fig. 7) [19,20].

Transient epiphora during the first postoperative week is a common secondary symptom after rhinoplasty. It is caused by postoperative edema, not by damage to the lacrimal drainage system, and it therefore tends to recover spontaneously [21]. Sachs reported that 10 out of 500 patients undergoing rhinoplasty (2\%) had transient epiphora that resolved spontaneously within 6 months. None of the patients had symptoms persisting longer than 8 months after the operation. According to that report, lacrimal system injury may occur either by subperiosteal tunneling on the lateral nasal wall or during lateral osteotomies with a saw. Therefore, it was suggested that a fine osteotomy instrument (less than $4 \mathrm{~mm}$ ) could be used without subperiosteal tunneling to reduce the risk of lacrimal system injuries [22]. A study analyzing the anatomic integrity of the bone structure around the lacrimal drainage system using $\mathrm{CT}$ and active transport dacryocystography in 20 patients after nasal osteotomy reported that the bone structure was preserved and free flow of contrast medium was observed from the lacrimal fossa to the inferior meatus. The average distance from the lacrimal drainage system to the lateral osteotomy site was $7-8.8 \mathrm{~mm}$ [23]. Sarialtin et al. [24] measured the distance between the lacrimal system and the lateral osteotomy line in order to determine the safe and ideal osteotomy level. They also evaluated the relationship of this safe osteotomy level with the lacrimal system using a three-dimensional model, and reported that the mean safety margin between the lateral osteotomy line and the anterior lacrimal crest was $6.0 \mathrm{~mm}$ (range, $4.5-7.5 \mathrm{~mm}$ ) on the right side and $6.0 \mathrm{~mm}$ (range, $4.5-7.4 \mathrm{~mm}$ ) on the left side in females, and $6.7 \mathrm{~mm}$ (range, $5.0-8.4 \mathrm{~mm}$ ) on the right side and $6.7 \mathrm{~mm}$ (range, $5.0-8.4 \mathrm{~mm}$ ) on the left side in males. They recommended three-dimensional CT as a preoperative evaluation and planning tool that makes the operative procedure easier to perform. In Asian rhinoplasty, there is a risk of damaging the lacrimal sac by making unintended fractures while manipulating patients' small and thick nasal bones. Although we have observed patients with transient epiphora after nasal osteotomy during 17 years of surgical experience, we have not observed any cases of permanent epiphora or damage of the lacrimal system among more than 2,000 osteotomy patients (Fig. 8) [6,25].

\section{MIDDLE VAULT}

\section{Upper lateral cartilage}

The upper lateral cartilage is a pair of triangular structures that not only play a major role in the anatomical shape of the nose, but also help to maintain the airway by contributing to the internal valve formed through the internal nasal cavity. The upper lateral cartilage and the septal cartilage are attached to each other. Specifically, the upper lateral cartilage is connected with the anterior or dorsal surface of the septal cartilage along $80 \%$ of the cephalic portion in terms of total length and separated only at the remaining $20 \%$ of the caudal portion. Approximately $2-11 \mathrm{~mm}$ of the cephalic portion is located beneath the nasal bone. The periosteum of the nasal bone and the perichondrium of the upper lateral cartilage connect with each other as a continuum (Fig. 9) [2,26].

A study analyzing the connection of the upper lateral cartilage and the dorsal septum through both gross dissection and histological specimens found a cleft between the upper lateral cartilage and the dorsal septum. The fibrous tissue in the cleft was perichondrium. The cartilaginous dorsum shifts its shape from a broad $\mathrm{Y}$ or $\mathrm{T}$ shape underneath the bony dorsum to a $\mathrm{Y}$ shape at the mid-vault and to a narrower I shape caudally (Fig. 10) [26]. 

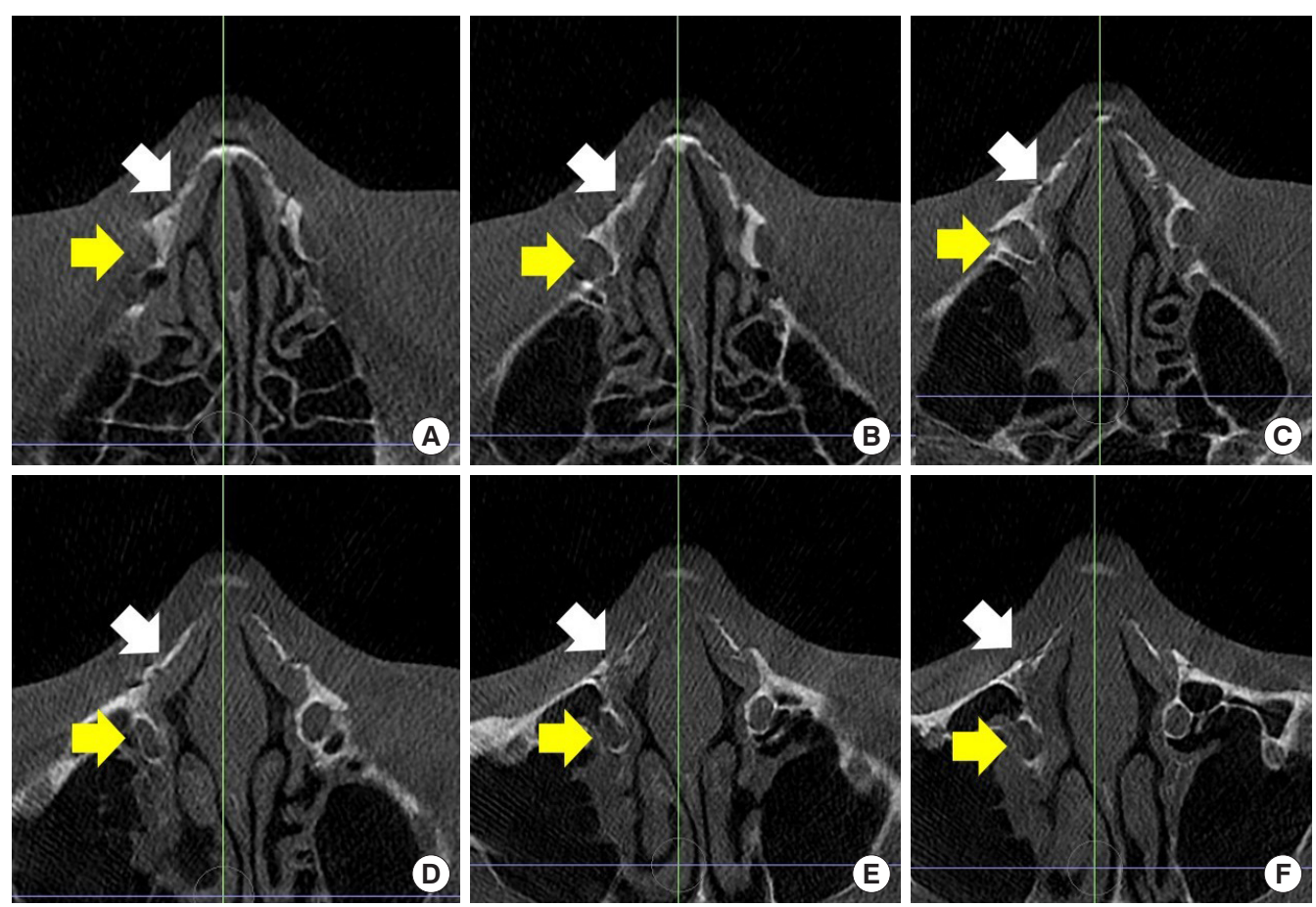

Fig. 8. (A-F) Serial computed tomography scans showing the relationship between the lateral osteotomy line and lacrimal drainage. Lateral osteotomy site (white arrow), Lacrimal sac and duct (yellow arrow).
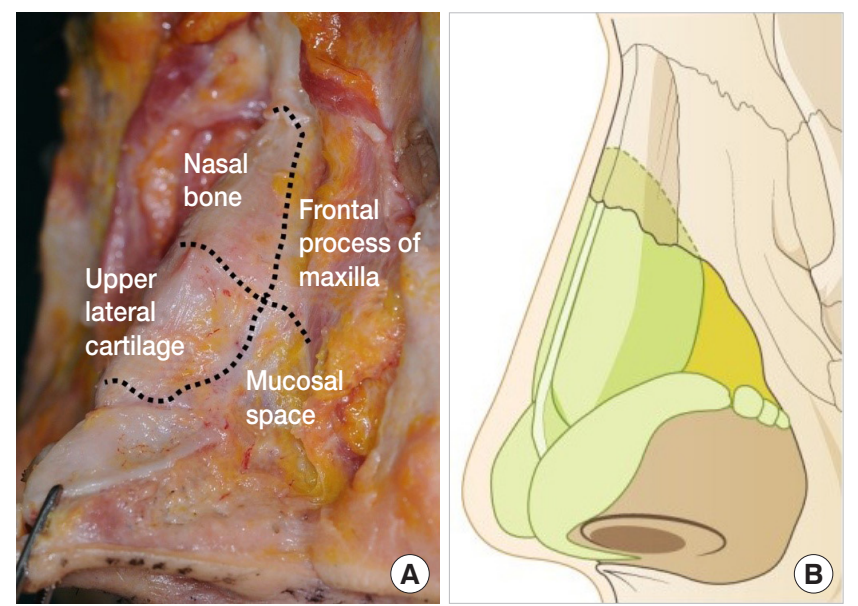

Fig. 9. Upper lateral cartilage. (A) Cadaver. (B) Illustration.

In general, the lateral border of the upper lateral cartilage corresponds to the caudal border of the suture line between the nasal bones and the frontal process of the maxilla. The lateral margin of the upper lateral cartilage starts from the nasal bone and the frontal process of the maxilla, moving away from the pyriform aperture as it descends. The cephalic border is the only part of the upper lateral cartilage that is attached to the nasal bone, whereas the caudal portion has no support from the bony structure, and it has less attachment to the septum from the sides downwards. There is an inverse relationship between the size of the mucosal space and the lateral extension of the
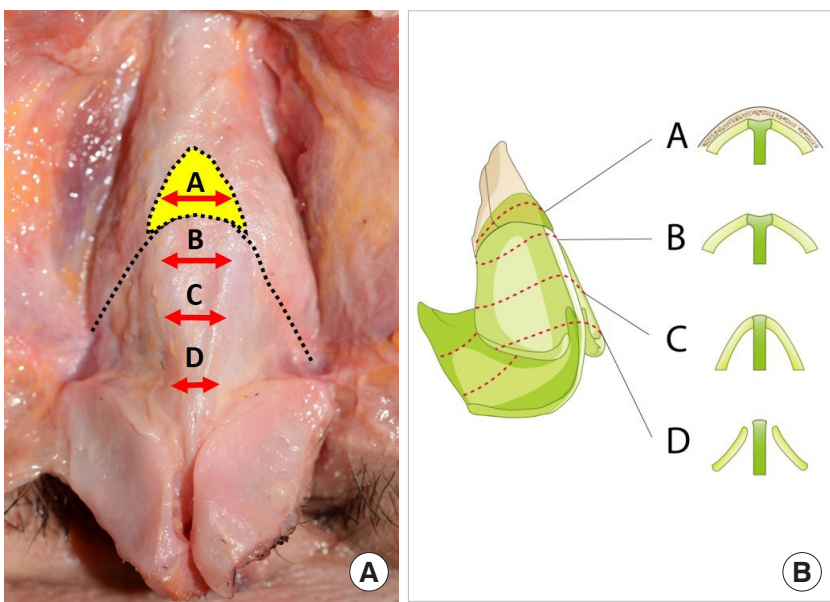

A)

(B)

Fig. 10. Connection of the upper lateral cartilage and the dorsal septum. (A) Cadaver. (B) Illustration. The cartilaginous dorsum shifts from a broad $\mathrm{Y}$ or $\mathrm{T}$ shape underneath the bony dorsum to a $\mathrm{Y}$ shape at the mid-vault and to a narrower I shape caudally.

caudal portion: the larger the cartilage, the smaller the mucosal space $[2,26]$.

The caudal border of the upper lateral cartilage forms the scroll junction with the lower lateral cartilage and is also crucial in establishing the internal valve [2,27-29]. Understanding the relationship between the medial-caudal parts of the upper lateral cartilage and the septal cartilage is vitally important for preserving the function of the internal valve (Fig. 11). The upper lateral cartilage is thin and separated from the septum, as 


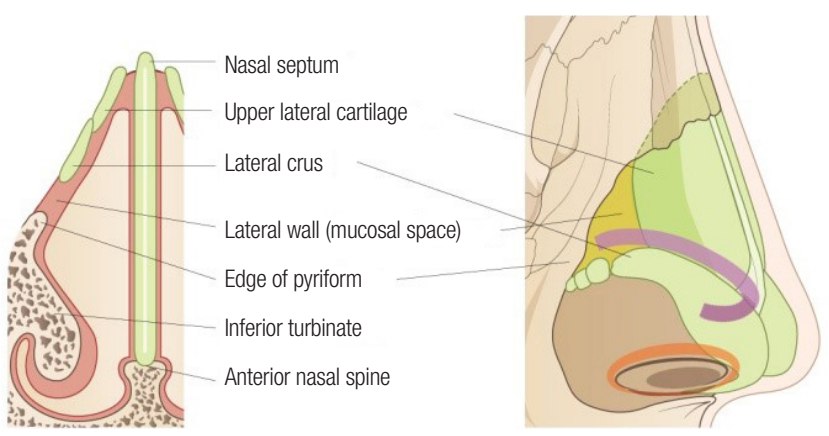

Fig. 11. Anatomical composition of the internal valve.

the medial-caudal part makes an inverted V-shaped angle with the septal cartilage in the frontal view. This critical structure makes the internal valve sufficiently movable for efficient respiration. The middle vault supports the movement of the internal valve by separating the upper lateral cartilage from the septal cartilage at the caudal end. The motion of the internal valve depends on coordination between the compressor and the dilator muscles during the respiration. It is made narrower by the medial movement of the lateral wall in the middle vault during shallow inspiration, and even narrower with deep inspiration, while voluntary dilator function prevents complete collapse of the valve during forced inspiration [30]. The inspiratory airflow is the fastest near the internal nasal valve and mainly passes between the inferior and superior turbinates. Expiratory airflow spreads in the nasal cavity while forming turbulent flow, which differs from that formed by inspiratory airflow. Forced nasal inspiration carries mucus towards the nasopharyngeal cavity and discharges mucous secretions from the middle meatus.

\section{Keystone area}

The keystone represents the union of the bony and cartilaginous framework of the nose. Anatomically, this unique triangular union consists of the paired nasal bones, the perpendicular plate of the ethmoid, and their fusion with the cartilaginous middle vault, including the upper lateral cartilages and the cartilaginous septum [31]. It is a critical anatomical structure providing stability at the osseocartilaginous junction (Fig. 12).

The overlapping length of the mid-portion between the septal cartilage and the nasal bone has been reported to range from 3 to $15 \mathrm{~mm}$. Kim et al. [32] reported that the overlapping length was $7.6 \pm 1.9 \mathrm{~mm}$ in 21 Korean cadavers. Simon et al. [33] showed a $6.5 \mathrm{~mm}$ overlapping length of the nasal bone with the septal cartilage on average. Natvig et al. [34] reported over 9 $\mathrm{mm}$ of overlap in the midline using cross-sections through the upper lateral cartilage-nasal bone junction; they also noted that the overlap tapered laterally, terminating in an end-to-end opposition. Palhazi et al. [35] reported that the average length of

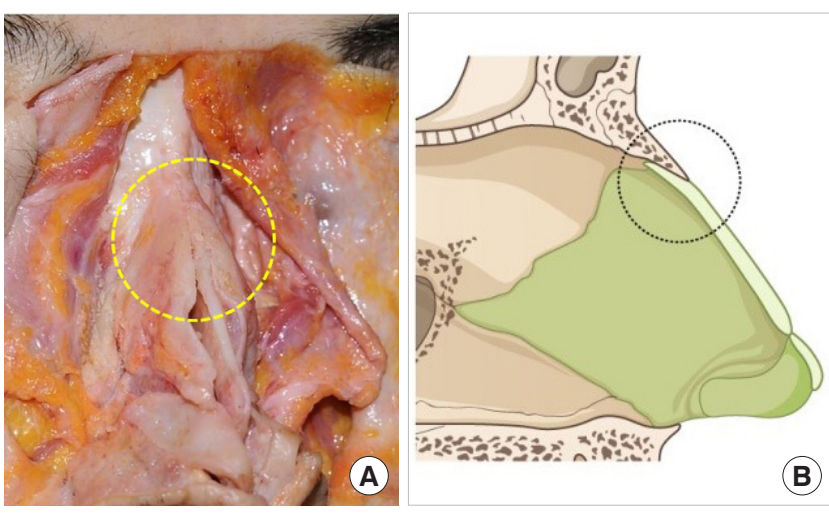

Fig. 12. Keystone area. (A) Cadaver. (B) Illustration.
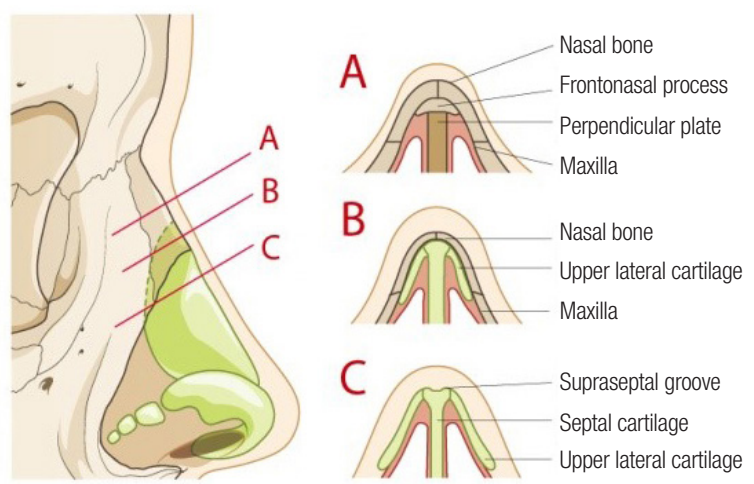

Fig. 13. Anatomical relationships around the keystone area.

the overlap of the bony-cartilaginous portion along the midline was $8.9 \mathrm{~mm}$ (range, $4-14 \mathrm{~mm}$ ) in 15 cadavers. Another study by Gerbault et al. [36] showed that the overlapping of bone over the upper lateral cartilage ranged from 6 to $20 \mathrm{~mm}$ in longitudinal length, with an average of $12 \mathrm{~mm}$. In Asian reports, the cephalocaudal length of the overlapping area between the upper lateral cartilage and the nasal bone was $7 \mathrm{~mm}$ (range, 4-10 $\mathrm{mm}$ ) in the midline, and $3.1 \mathrm{~mm}$ (range, 0-7 mm) in the paramedian area in a study by Kim et al. [37] involving the dissection of 18 Korean cadavers. Han et al. [38] reported that the nasal bone-upper lateral cartilage overlap was $6.47 \pm 2.50 \mathrm{~mm}$ in the midline, $3.53 \pm 2.23 \mathrm{~mm}$ on the left side, and $3.81 \pm 2.56$ $\mathrm{mm}$ on the right side in a study of 16 Chinese cadavers. In summary, the length of overlap between the nasal bone and cartilaginous septum tends to be shorter in Asians according to previous research. Therefore, the risk of unintentionally damaging the bony-cartilaginous junction during hump resection is higher (Fig. 13).

The anatomy of the keystone area reflects its embryology. The nasal skeleton in neonates is cartilaginous and extends from the cartilaginous primordium of the cranial base [39]. The downward covering of the nasal bones over the cartilaginous capsule explains the broad overlap of the bony and cartilaginous vault. 


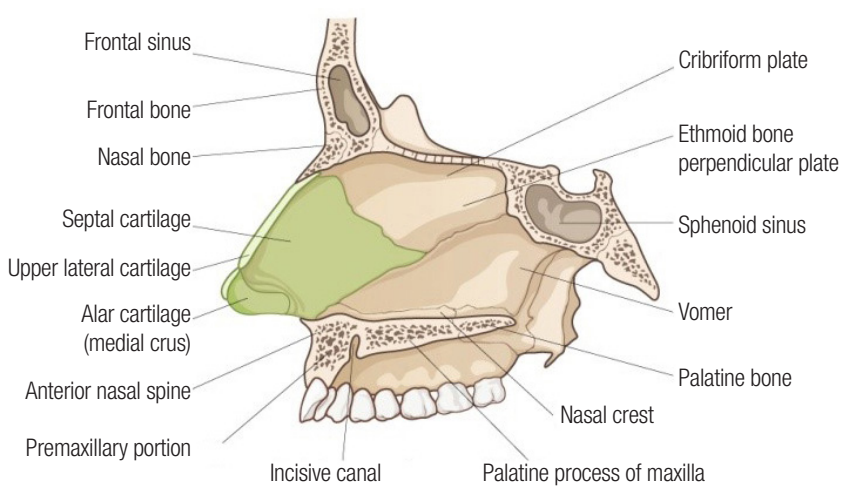

Fig. 14. Anatomical composition of the septum.

The cartilaginous capsule is absorbed toward the cephalic direction, and its remaining parts develop into the cartilaginous vault. Therefore, the bony and cartilaginous vaults are not simply conjoined, but rather have an overlapping integration. This relationship can be described as a chondro-osseous joint, with the bony cap separated from the cartilaginous vault by fusion of the periosteum and perichondrium $[1,2,35]$. In embryology, nasal growth depends upon expansion of the septum, rather than growth of the nasal bones. In childhood, nasal height is due mainly to the nasal bone. During puberty, the cartilaginous septum functions as the dominant growth center of the midface. The nose undergoes radical changes caused by the growth of the maxilla, and the nasal hump results from the upward thrust of the underlying cartilaginous vault, rather than from a contribution by the nasal bones. In short, Daniel insisted that there is no bony hump, only a bony cap that covers a cartilaginous hump $[2,4,35,40]$.

\section{Septum}

The septum, a complex osseocartilaginous structure, separates the nasal cavity into two chambers. The septum is composed of the septal cartilage and four bones, including the perpendicular plate of the ethmoid, the vomer, the nasal crest of the maxilla, and the nasal crest of the palatine bone (Fig. 14). It forms a pillar for the nasal dorsum to stand straight in the facial midline while dividing the nasal cavity. The cephalic portion of the septum is rigid and fixed, while the caudal portion is flexible and semifixed, enabling the septum to serve as a buffer against external forces. The septum can be divided into three components: membranous, cartilaginous, and bony. The membranous septum has no cartilage, but it has intrinsic muscles and the depressor septi nasi muscle. The cartilaginous septum has septal cartilage sandwiched between the nasal mucosa. It is somewhat rigid, but also flexible enough to withstand external forces. It is vulnerable to deformation or deviation resulting from postop-
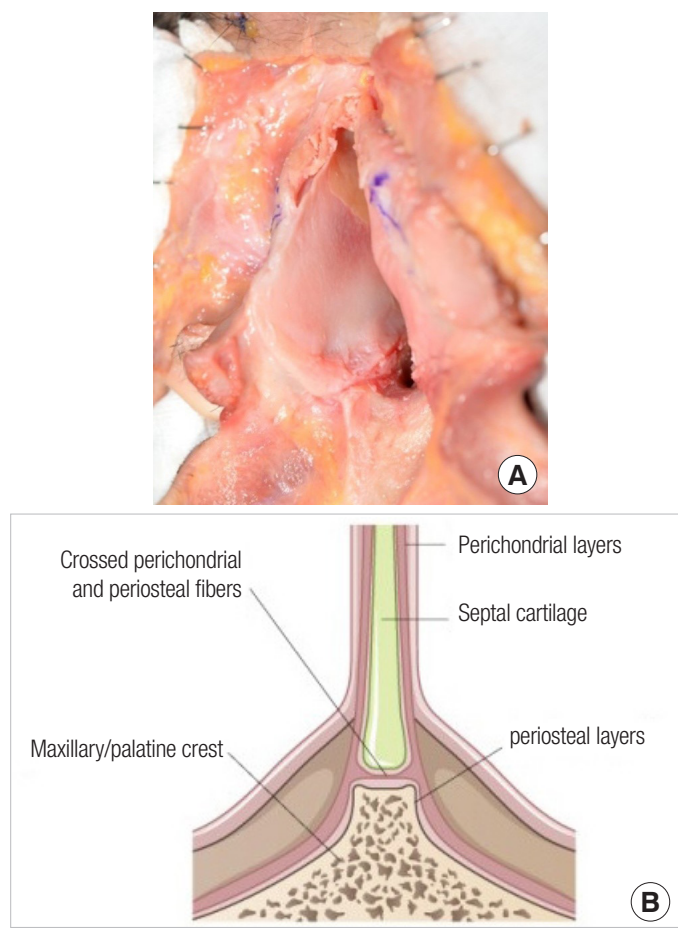

Fig. 15. Connection between the septal cartilage and maxillary crest along with the palatine crest as a tongue-in-groove pattern. (A) Cadaver. (B) Illustration.

erative or posttraumatic injury or hematoma. A trivial childhood trauma, even without fracture, during the growth phase may affect the development of the septal cartilage, which may present with deviation or bending caused by scar formation during the healing process [41]. The septal cartilage comes into contact with the perpendicular plate of the ethmoid in an endto-end pattern but forms a much stronger contact with the vomer in a tongue-in-groove pattern. Mucoperichondrium is tightly attached to the septal cartilage from the caudal border to the 1-1.5 cm cephalic portion of the vestibular mucosa, but it becomes looser toward the inner septal mucosa. The connection between the septal cartilage and the maxillary crest, as well as with the palatine crest, is formed in a tongue-in-groove pattern that is easy to dislocate during dissection (Fig. 15).

Nasal growth peaks at 13.1 years and matures at 15.8 years in $98 \%$ of the female population, while it peaks at 14.7 years and matures at 16.9 years in $98 \%$ of the male population. Therefore, it is recommended to conduct septal interventions after maturation [42].

The septal cartilage is classified as hyaline cartilage on histology. As with other cartilage tissue, the septum shows changes with aging. Although the amount of hydroxyproline, its main component, does not change substantially, that of glycosaminoglycan (GAG) decreases significantly with aging. As individuals become older, the equilibrium modulus decreases and the hy- 
draulic permeability increases. These changes are related to calcification or ossification of the cartilage. Therefore, when operating on elderly patients, surgeons should be aware that the cartilage might be vulnerable during manipulation. Therefore, appropriate precautions should be considered in older patients [43].

The shape and thickness of the septum differs among individuals with an I, T, or Y shape at the cross-section depending upon dorsal width. The medial margin of the upper lateral cartilage and the antero-lateral margin of the septal cartilage are fused as intermingling cartilaginous tissue and are then connected with fibrous tissue at the caudal third (Fig. 10) $[1,2,6,26]$. The angle between the caudal part of the upper lateral cartilage and the septal cartilage, which is referred to as the internal nasal valve, is usually $15^{\circ}$. The internal nasal valve controls the airstream through the medial movement of the caudal margin of the upper lateral cartilage during inspiration and its lateral movement during expiration.
Although it is accepted that the septal cartilage harvested from Asians is smaller and thinner than that harvested from Caucasians, the difference in the size and thickness of the septal cartilage remains within a quite reasonable range, based on a review of the literature and the authors' experience (Fig. 16) [44]. Kim et al. [45] reported that the average height and length of the septal cartilage were $22.1 \mathrm{~mm}$ and $28 \mathrm{~mm}$, respectively, in a Korean cadaveric study. The maximal amount available for harvest was reported to be $12.1 \times 18.0 \mathrm{~mm}$ on average when the width of the remnant L-strut was about $10 \mathrm{~mm}$. Hwang et al. [46] reported that average height and length of the septal cartilage were $33.1 \pm 5.3 \mathrm{~mm}$ and $29.9 \pm 4.7 \mathrm{~mm}$, respectively. The septal cartilage was found to be thickest at the septal base in front of the vomer, which measures approximately 2.19-3.03 $\mathrm{mm}$, and the thinnest part was found to be roughly in the lower third of the septum, just above the septal base, which measured about 1.03-1.22 mm. In contrast, in a Brazilian cadaveric study, de Pochat et al. [47] reported that the average height and length
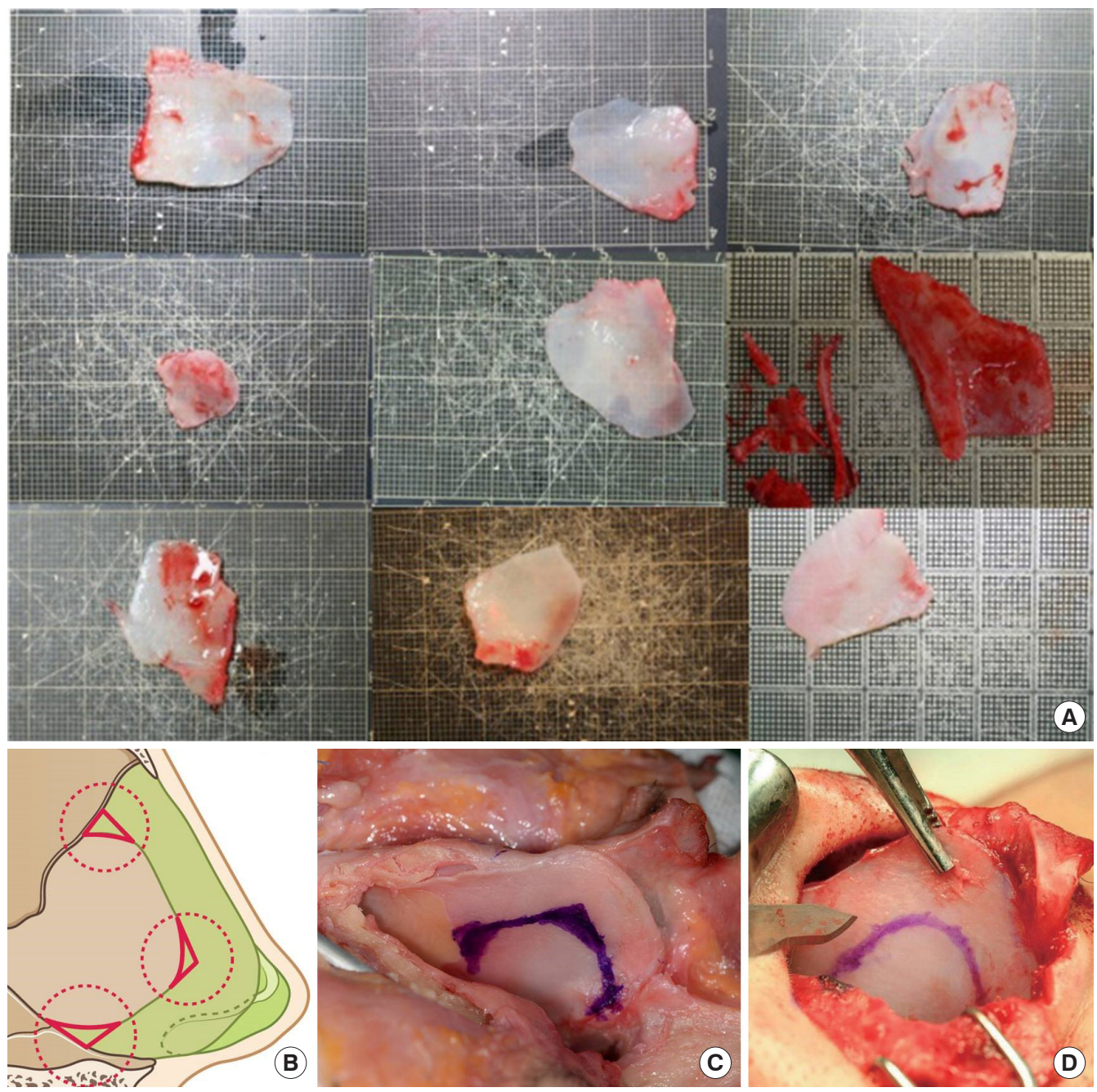

Fig. 16. Harvest of septal cartilage. (A) Various sizes of harvested septal cartilage. (B) Illustration. (C) Cadaver. (D) Intraoperative view. 
of the septal cartilage were $32.5 \mathrm{~mm}$ and $35.4 \mathrm{~mm}$, respectively, and that the average thickness ranged from $1.3 \mathrm{~mm}$ to $2.7 \mathrm{~mm}$. Mowlavi et al. [48] reported that the thickest and thinnest areas of septal cartilage were $2.7 \mathrm{~mm}$ and $1.3 \mathrm{~mm}$, respectively. However, those studies analyzed an insufficient number of patients to conclude definitively that the septal cartilage is considerably smaller and thinner in Asians. Moreover, it might be challenging for surgeons to operate on the nose of Asian patients because the septal cartilage varies among individuals and because Asian rhinoplasty requires considerable tip projection while using a relatively small amount of cartilage (Table 2).

When harvesting the septum, the stability of the remnant Lstrut is more important than the amount of harvested septal cartilage. It is helpful to preserve the edge as a smooth connection between the dorsal cutting line and caudal cutting line in order to enhance the stability of the L-strut, as described below (Fig. 16). In particular, the cartilage beneath the keystone area should be maximally preserved to maintain the stability of septal support and to prevent complications such as saddle nose deformity [38]. According to Mau et al. [49], a wider L-strut and a greater extent of overlap in the junction at the keystone will improve stability against tensile stress.

\section{Turbinates}

The inferior turbinate is a dynamic structure that controls the direction of the nasal airstream and provides the most resistance of the three turbinates (superior, middle, and inferior). The head of the inferior turbinate, which is quite large (14 mm in height) and extremely dynamic, is located at the critical internal valvular area (Fig. 17). The soft tissue of the turbinate is composed of vascular components and smooth muscle [50]. The blood supply to the inferior turbinate is composed of anterior and posterior contributions. The anterior ethmoid artery and lateral nasal artery provide the anterior blood supply, whereas the sphenopalatine artery provides the posterior supply [51]. The inferior turbinate warms and humidifies inhaled air. As air passes through the nasal valve, it is directed toward the surface of the inferior turbinate. The laminar airflow passing over the turbinate creates resistance, which causes nasal mucus production, thereby providing humidification. The normal nose can increase the humidity of inhaled air from $0 \%$ externally to near $100 \%$ at the level of the nasopharynx. This fact may explain the significant dryness-related symptoms that frequently occur after total turbinectomy [52].

Normal nasal respiration is possible if intranasal resistance is within the normal range. Nasal obstruction might occur if the resistance is higher or lower than ordinary range. Narrowing of the intranasal pathway due to collapse of middle vault, septal deviation, or a disorder of the nasal valve increases intranasal resistance, which causes nasal obstruction. Ironically, severely

Table 2. Studies reporting measurements of human septal cartilage

\begin{tabular}{|c|c|c|c|c|c|c|}
\hline Author & No. of specimens & $\begin{array}{l}\text { Length of septal } \\
\text { cartilage (mm) }\end{array}$ & $\begin{array}{l}\text { Height of septal } \\
\text { cartilage (mm) }\end{array}$ & $\begin{array}{l}\text { Surface area } \\
\qquad\left(\mathrm{mm}^{2}\right)\end{array}$ & $\begin{array}{l}\text { Thickest portion } \\
(\mathrm{mm})\end{array}$ & $\begin{array}{l}\text { Thinnest portion } \\
\text { (mm) }\end{array}$ \\
\hline Kim et al. [45] & 10 Korean cadavers & 28 & 22.1 & $\begin{array}{c}\text { 432-910 } \\
\text { (average 627.2) }\end{array}$ & - & - \\
\hline Hwang et al. [46] & 14 Korean cadavers & $33.1 \pm 5.3$ & $29.9 \pm 4.7$ & - & $\begin{array}{l}2.19-3.03 \\
\text { (septal base) }\end{array}$ & $\begin{array}{l}\quad 0.74-0.97 \\
\text { (at 20\% of the septal height) }\end{array}$ \\
\hline de Pochat et al. [47] & 14 Brazilian cadavers & 35.14 (average) & 32.5 & 933.11 & 1.71 & 1.04 \\
\hline Mowlavi et al. [48] & 11 Caucasian cadavers & $31.0 \pm 4.0$ & $26.0 \pm 3.0$ & - & $2.7 \pm 0.2$ & $\begin{array}{c}1.3 \pm 0.2 \\
\text { (along the central portion) }\end{array}$ \\
\hline
\end{tabular}

Values are presented as mean $\pm S D$ or range.
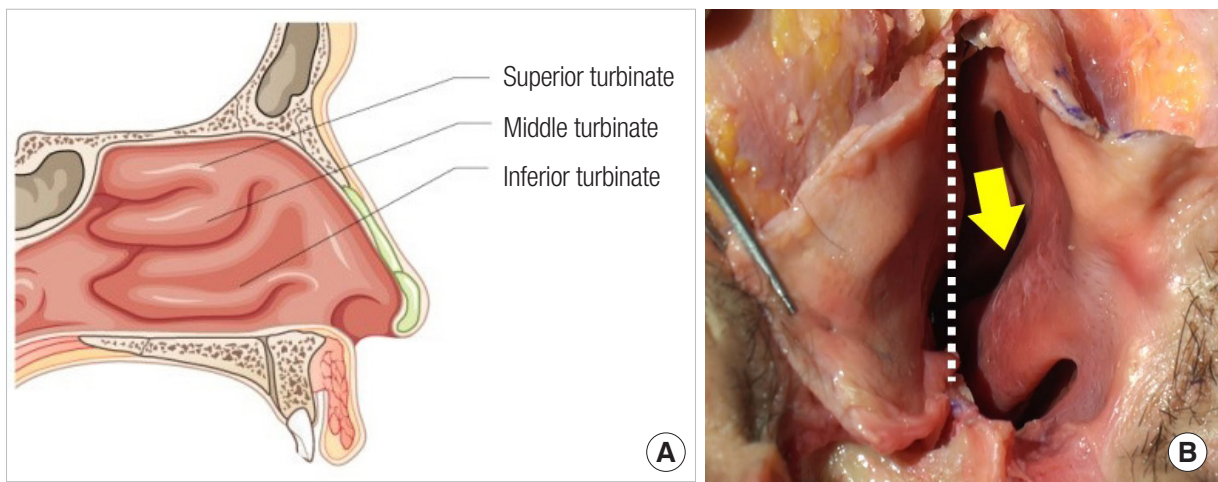

Fig. 17. Turbinates. (A) Illustration. (B) Cadaver. Inferior turbinate (yellow arrow), removed septum (dotted white line). 
low intranasal resistance due to atrophic rhinitis after excessive turbinectomy might also cause nasal obstruction. Nasal obstruction may occur as part of the physiologic nasal cycle, which involves periodic congestion and decongestion of cavernous tissue of the nasal mucosa, or due to pathologic problems. The rhythm of the nasal cycle is thought to be controlled by a central regulator located in the hypothalamus, which causes bilateral vasoconstriction of the nasal mucosa (Fig. 18) [53]. The physiologic nasal cycle is altered by changes in humidity, temperature, and the patient's condition. According to reports, the cycle of repetitive constriction and inflation of the nasal mucosa varies from 25 minutes to 4 hours [54]. In this cycle, as one side becomes congested, resistance increases and airflow subsequently decreases, whereas on the other side, resistance decreases as the contralateral mucosa constricts, leading to an increase in the airflow. Healthy individuals do not recognize the nasal cycle, but a patient with structural problems such as septal deviation may complain of unilateral or bilateral nasal obstruction during the nasal cycle. It is important to understand the compensatory enlargement of the inferior turbinate under the influence of septal deviation. Unless septal devi-

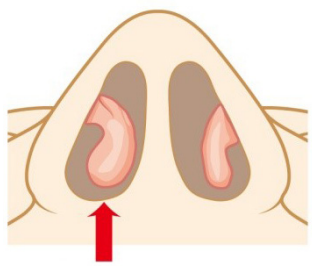

Right turbinate hypertrophy

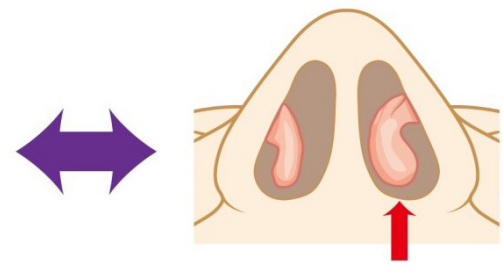

Left turbinate hypertrophy
Fig. 18. Human nasal cycle. ation and a hypertrophied inferior turbinate are corrected simultaneously, nasal obstruction might become aggravated afterwards (Fig. 19).

A representative symptom of rhinitis, nasal obstruction results from increased resistance of the nasal airway. Therefore, turbinoplasty aims at widening the nasal airway to improve the smoothness of respiration. A small change in the volume or position of the inferior turbinate may sometimes improve nasal airway considerably. There are various surgical techniques for inferior turbinoplasty, including total turbinectomy, lateralization of the turbinate using the out-fracture technique, electrocautery or radiofrequency ablation, and laser coblation. Moreover, other methods involve cryosurgery, inferior turbinate submucosal resection, resection using a micro-debrider, and turbinate micro-fragmentation (Fig. 20). Full turbinectomy or radical turbinectomy was used in the past. However, this procedure was accompanied by excessive bleeding, delayed recovery, and potential atrophic rhinitis or even empty nose syndrome; therefore, it is hardly used at the present. More conservative methods that spare the nasal mucosa have recently become more popular. Lateralization using out-fracture of the inferior turbinate is the technically simplest and most effective method. It is a minimally destructive procedure compared with other techniques because it preserves the nasal mucosa and does not interfere with muco-ciliary function [55-57]. Electrocautery uses radiofrequency to reduce mucosal volume. This spares the epithelial surface because the electric energy acts focally within the mucosa, thereby preserving ciliary function $[58,59]$. Electrocautery, radiofrequency ablation, laser turbinectomy, and cryosurgery are used in cases of mucosal hypertrophy. In contrast, infe-

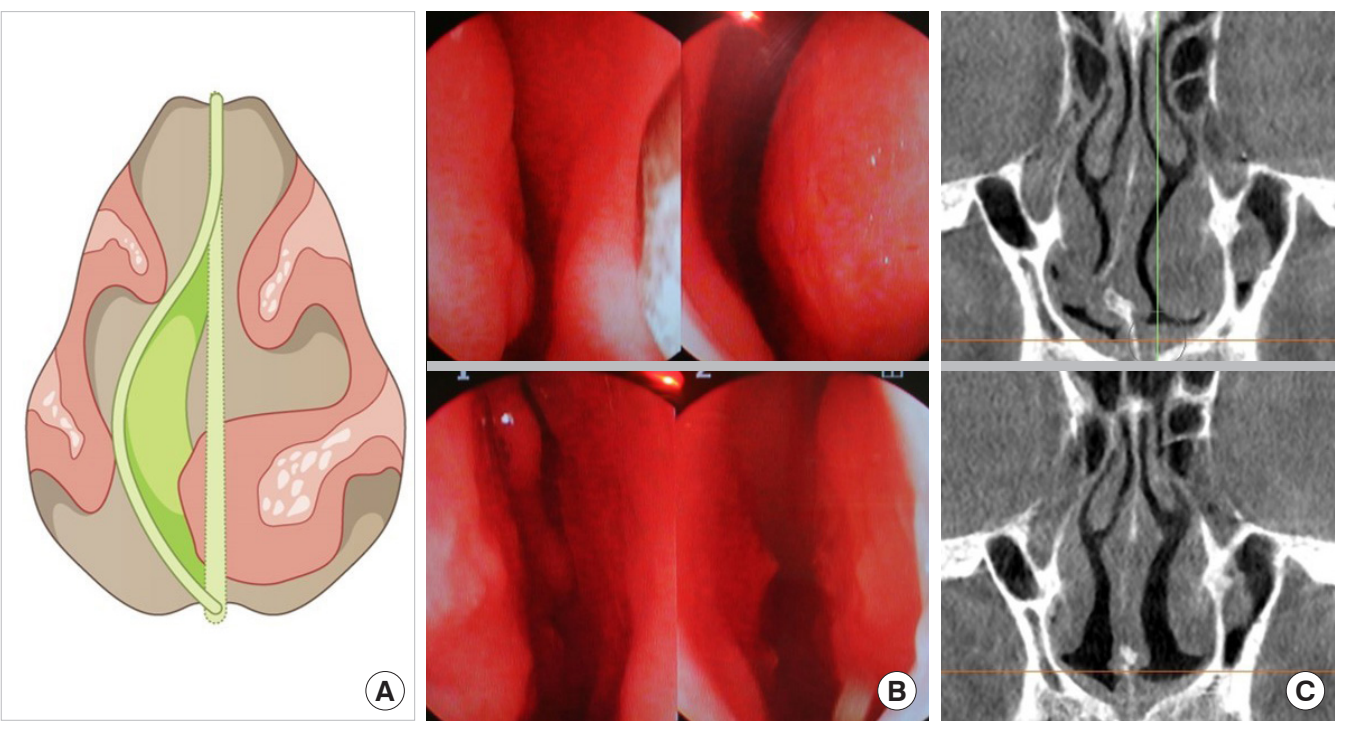

Fig. 19. Compensated enlargement of the inferior turbinate should be corrected concomitantly during septoplasty. (A) Illustration. (B) Endoscopic view, preoperatively (top) and postoperatively (bottom). (C) Computed tomography scan, preoperatively (top) and postoperatively (bottom). 

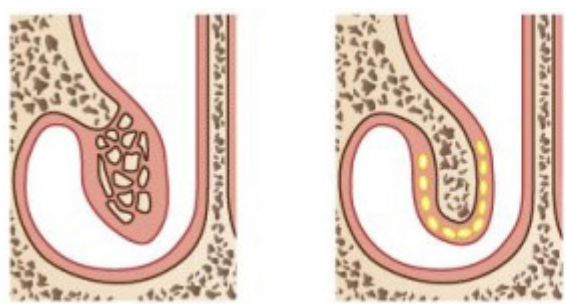

Microfragmentation

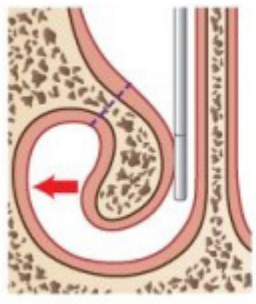

Outfracture
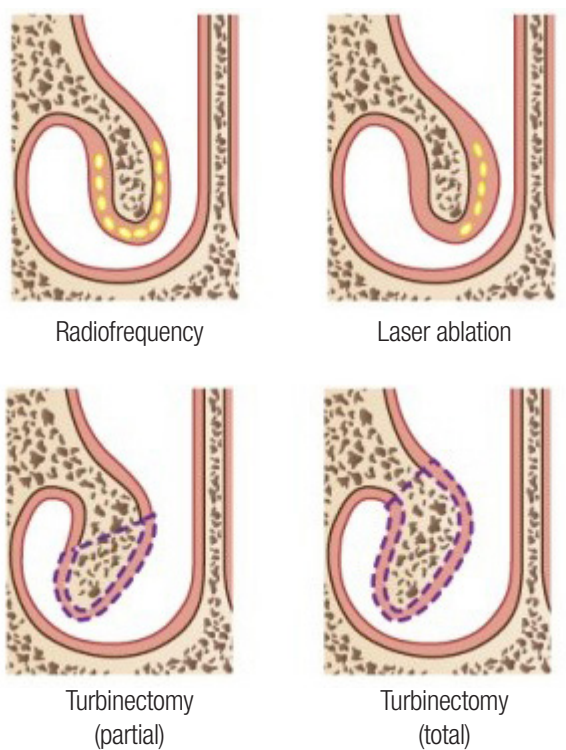

Laser ablation

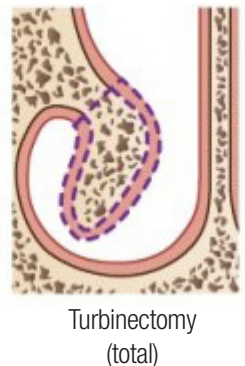

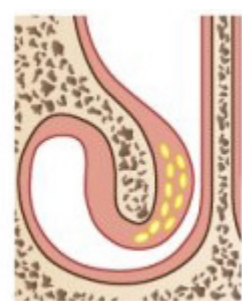

Bipolar coagulation

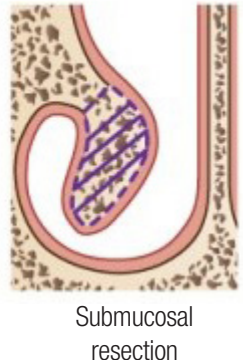

Fig. 20. Various methods of turbinate management.

rior turbinate submucosal resection, inferior turbinate submucosal resection using a micro-debrider, lateralization of the inferior turbinate, and turbinate micro-fragmentation are performed in cases of conchal hypertrophy [60].

\section{NOTES}

\section{Conflict of interest}

No potential conflict of interest relevant to this article was reported.

\section{Ethical approval}

This study was performed in accordance with the principles of the Declaration of Helsinki. Written informed consent was obtained.

\section{Patient consent}

The patients provided written informed consent for the publication and the use of their images.

\section{ORCID}

Taek Kyun Kim https://orcid.org/0000-0002-3213-9803

Jae Yong Jeong https://orcid.org/0000-0001-5654-4443

\section{REFERENCES}

1. Daniel RK, Letourneau A. Rhinoplasty: nasal anatomy. Ann Plast Surg 1988;20:5-13.

2. Daniel RK, Palhazi P. Rhinoplasty: an anatomical and clinical atlas. Cham: Springer International Publishing; 2018.
3. Harshbarger RJ, Sullivan PK. Lateral nasal osteotomies: implications of bony thickness on fracture patterns. Ann Plast Surg 1999;42:365-70.

4. Gerbault O, Daniel RK, Palhazi P, Kosins AM. Reassessing surgical management of the bony vault in rhinoplasty. Aesthet Surg J 2018;38:590-602.

5. Lee SH, Yang TY, Han GS, Kim YH, Jang TY. Analysis of the nasal bone and nasal pyramid by three-dimensional computed tomography. Eur Arch Otorhinolaryngol 2008;265:421-4.

6. Jeong JY, Kim TK. Rebuilding nose: rhinoplasty for Asians. Uijeongbu: Medic Medicine; 2018.

7. Lazovic GD, Daniel RK, Janosevic LB, Kosanovic RM, Colic MM, Kosins AM. Rhinoplasty: the nasal bones - anatomy and analysis. Aesthet Surg J 2015;35:255-63.

8. Papesch E, Papesch M. The nasal pyriform aperture and its importance. Otorhinolaryngol Head Neck Surg 2016;1:89-91.

9. Lang J, Baumeister R. Postnatal growth of the nasal cavity. Gegenbaurs Morphol Jahrb 1982;128:354-93.

10. Ofodile FA. Nasal bones and pyriform apertures in blacks. Ann Plast Surg 1994;32:21-6.

11. Hwang TS, Song J, Yoon H, Cho BP, Kang HS. Morphometry of the nasal bones and piriform apertures in Koreans. Ann Anat 2005;187:411-4.

12. Webster RC, Davidson TM, Smith RC. Curved lateral osteotomy for airway protection in rhinoplasty. Arch Otolaryngol 1977;103:454-8.

13. Guyuron B. Nasal osteotomy and airway changes. Plast Reconstr Surg 1998;102:856-60.

14. Gubisch W. Mastering advanced rhinoplasty. Cham: Springer; 2018. 
15. Jones LT. An anatomical approach to problems of the eyelids and lacrimal apparatus. Arch Ophthalmol 1961;66:111-24.

16. Groessl SA, Sires BS, Lemke BN. An anatomical basis for primary acquired nasolacrimal duct obstruction. Arch Ophthalmol 1997;115:71-4.

17. Groell R, Schaffler GJ, Uggowitzer M, Szolar DH, Muellner K. CT-anatomy of the nasolacrimal sac and duct. Surg Radiol Anat 1997;19:189-91.

18. Whitnall SE. The anatomy of the human orbit and accessory organs of vision. London: Oxford University Press; 1932.

19. Chastain JB, Sindwani R. Anatomy of the orbit, lacrimal apparatus, and lateral nasal wall. Otolaryngol Clin North Am 2006; 39:855-64.

20. Cohen AJ, Mercandetti M, Brazzo BG. The lacrimal system: diagnosis, management and surgery. New York: Springer; 2006.

21. Thomas JR, Griner N. The relationship of lateral osteotomies in rhinoplasty to the lacrimal drainage system. Otolaryngol Head Neck Surg 1986;94:362-7.

22. Sachs ME. Lacrimal system injury secondary to cosmetic rhinoplasty. Adv Ophtal Plast Reconstr Surg 1984;3:301-5.

23. Yigit O, Cinar U, Coskun BU, Akgul G, Celik D, Celebi I, et al. The evaluation of the effects of lateral osteotomies on the lacrimal drainage system after rhinoplasty using active transport dacryocystography. Rhinology 2004;42:19-22.

24. Sarialtin Y, Ortak T, Oz C, Kus E, Yunusoglu GU, Dogan S, et al. Radiological assessment of the lateral osteotomy line-lacrimal system distance on three-dimensional models. J Craniomaxillofac Surg 2019;47:1608-16.

25. Jeong JY, Ha Y, Kim S, Yang HJ, Oh SH. Availability and safety of osteotomy in esthetic rhinoplasty of East Asian patients. Ann Plast Surg 2018;81:141-5.

26. Straatsma BR, Straatsma CR. The anatomical relationship of the lateral nasal cartilage to the nasal bone and the cartilaginous nasal septum. Plast Reconstr Surg (1946) 1951;8:433-55.

27. Oneal RM, Beil RJ Jr, Izenberg PH, Schlesinger J. Surgical anatomy of the nose. Oper Tech Plast Reconstr Surg 2000;7:158-67.

28. Lam SM, Williams EF 3rd. Anatomic considerations in aesthetic rhinoplasty. Facial Plast Surg 2002;18:209-14.

29. Jeong JY. Tripod framework rebuilding in Asian nose: tip plasty using alar advancement technique. J Korean Soc Aesthetic Plast Surg 2010;16:125-38.

30. Bruintjes TD, van Olphen AF, Hillen B, Huizing EH. A functional anatomic study of the relationship of the nasal cartilages and muscles to the nasal valve area. Laryngoscope 1998;108: 1025-32.

31. Afrooz PN, Rohrich RJ. The keystone: consistency in restoring the aesthetic dorsum in rhinoplasty. Plast Reconstr Surg 2018; 141:355-363.
32. Kim CH, Jung DH, Park MN, Yoon JH. Surgical anatomy of cartilaginous structures of the Asian nose: clinical implications in rhinoplasty. Laryngoscope 2010;120:914-9.

33. Simon PE, Lam K, Sidle D, Tan BK. The nasal keystone region: an anatomical study. JAMA Facial Plast Surg 2013;15:235-7.

34. Natvig P, Sether LA, Gingrass RP, Gardner WD. Anatomical details of the osseous-cartilaginous framework of the nose. Plast Reconstr Surg 1971;48:528-32.

35. Palhazi P, Daniel RK, Kosins AM. The osseocartilaginous vault of the nose: anatomy and surgical observations. Aesthet Surg J 2015;35:242-51.

36. Gerbault O, Daniel RK, Kosins AM. The role of piezoelectric instrumentation in rhinoplasty surgery. Aesthet Surg J 2016;36: 21-34.

37. Kim IS, Chung YJ, Lee YI. An anatomic study on the overlap patterns of structural components in the keystone area in noses of Koreans. Clin Exp Otorhinolaryngol 2008;1:158-60.

38. Han Z, Wang F, Zhou C, Chou A. Anatomical study of the Chinese nasal keystone region. Aesthet Surg J 2019;39:595-602.

39. Poublon RM, Verwoerd CD, Verwoerd-Verhoef HL. Anatomy of the upper lateral cartilages in the human newborn. Rhinology 1990;28:41-5.

40. Verwoerd CD, Verwoerd-Verhoef HL. Rhinosurgery in children: developmental and surgical aspects of the growing nose. GMS Curr Top Otorhinolaryngol Head Neck Surg 2010;9: Doc05.

41. Holt GR. Biomechanics of nasal septal trauma. Otolaryngol Clin North Am 1999;32:615-9.

42. van der Heijden P, Korsten-Meijer AG, van der Laan BF, Wit HP, Goorhuis-Brouwer SM. Nasal growth and maturation age in adolescents: a systematic review. Arch Otolaryngol Head Neck Surg 2008;134:1288-93.

43. Rotter N, Tobias G, Lebl M, Roy AK, Hansen MC, Vacanti CA, et al. Age-related changes in the composition and mechanical properties of human nasal cartilage. Arch Biochem Biophys 2002;403:132-40.

44. Jeong JY. Obtaining maximal stability with a septal extension technique in East Asian rhinoplasty. Arch Plast Surg 2014;41: 19-28.

45. Kim JS, Jang PY, Choi TH, Kim NG, Lee KS. The dimension of the septal cartilage using the cadaver study. J Korean Soc Aesthetic Plast Surg 2006;12:29-32.

46. Hwang K, Huan F, Kim DJ. Mapping thickness of nasal septal cartilage. J Craniofac Surg 2010;21:243-4.

47. de Pochat VD, Alonso N, Figueredo A, Ribeiro EB, Mendes $\mathrm{RR}$, Meneses JV. The role of septal cartilage in rhinoplasty: cadaveric analysis and assessment of graft selection. Aesthet Surg J 2011;31:891-6. 
48. Mowlavi A, Masouem S, Kalkanis J, Guyuron B. Septal cartilage defined: implications for nasal dynamics and rhinoplasty. Plast Reconstr Surg 2006;117:2171-4.

49. Mau T, Mau ST, Kim DW. Cadaveric and engineering analysis of the septal L-strut. Laryngoscope 2007;117:1902-6.

50. King HC, Mabry RL. A practical guide to the management of nasal and sinus disorders. New York: Thieme; 1993.

51. Gil Z, Margalit N. Anteriorly based inferior turbinate flap for endoscopic skull base reconstruction. Otolaryngol Head Neck Surg 2012;146:842-7.

52. Downs BW. The inferior turbinate in rhinoplasty. Facial Plast Surg Clin North Am 2017;25:171-7.

53. Eccles R. A role for the nasal cycle in respiratory defence. Eur Respir J 1996;9:371-6.

54. Kumaran EM. Alteration in nasal cycle rhythm as an index of the diseased condition. In: Gaze DC, editor. Pathophysiology: altered physiological states. London: InTech; 2018. p. 23-34.

55. Bhandarkar ND, Smith TL. Outcomes of surgery for inferior turbinate hypertrophy. Curr Opin Otolaryngol Head Neck
Surg 2010;18:49-53.

56. Buyuklu F, Cakmak O, Hizal E, Donmez FY. Outfracture of the inferior turbinate: a computed tomography study. Plast Reconstr Surg 2009;123:1704-9.

57. Aksoy F, Yildirim YS, Veyseller B, Ozturan O, Demirhan H. Midterm outcomes of outfracture of the inferior turbinate. Otolaryngol Head Neck Surg 2010;143:579-84.

58. Hytonen ML, Back LJ, Malmivaara AV, Roine RP. Radiofrequency thermal ablation for patients with nasal symptoms: a systematic review of effectiveness and complications. Eur Arch Otorhinolaryngol 2009;266:1257-66.

59. Garzaro M, Pezzoli M, Pecorari G, Landolfo V, Defilippi S, Giordano C. Radiofrequency inferior turbinate reduction: an evaluation of olfactory and respiratory function. Otolaryngol Head Neck Surg 2010;143:348-52.

60. Chen YL, Tan CT, Huang HM. Long-term efficacy of microdebrider-assisted inferior turbinoplasty with lateralization for hypertrophic inferior turbinates in patients with perennial allergic rhinitis. Laryngoscope 2008;118:1270-4. 